\title{
COMPORTAMENTO DE CULTIVARES DE MANGA (Mangifera indica L.) EM RELAÇÃO À MALFORMAÇÃO' ${ }^{1}$
}

\author{
RONALDO POSELLAZACCARO ${ }^{2}$,LUIZCARLOS DONADIO ${ }^{3}$, ELIANA GERTRUDES MACEDOLEMOS $^{4}$, \\ DILERMANDOPERECIN ${ }^{5}$
}

RESUMO - A malformação da mangueira causada pelo fungo Fusarium subglutinans Wollenweb \& Reinking é provavelmente a doença que mais causa prejuízos à produção de manga no Brasil e em outros países produtores. Esse fungo foi isolado de uma plantamatriz da cultivar Tommy Atkins com avançados sintomas da doença, purificado e preparado para ser inoculado em 15 cultivares de manga nacionais e importadas. Inicialmente, foram inoculadas, em julho de 2000, 10 cultivares: Bourbon IAC - 100, Coração-de-Boi, Keitt, Parvin, Primor de Amoreira, Sensation, Smith, Surpresa, Tommy Atkins e Van Dyke. O segundo grupo foi inoculado em dezembro de 2000, com as cultivares: Adams, Bhadauran, Palmer, Princesa e Zill, e repetiu-se a inoculação com outras mudas das cultivares Primor de Amoreira, Sensation e Tommy Atkins, com a finalidade de se compararem as duas épocas de inoculação. Através dos dados obtidos com as plantas avaliadas nas duas épocas de inoculação, após 11 meses de observações, realizou-se o teste de médias Z para comparar a proporção de plantas doentes entre as cultivares, podendo-se concluir, com os resultados obtidos, que as cultivares Bhadauran, Palmer, Parvin, Sensation, Surpresa, Van Dyke e Zill apresentam menor porcentagem de plantas com sintomas de malformação ou menor progressão de sintomas em relação às outras cultivares inoculadas, para as condições de ambiente protegido em que foram realizados os ensaios.

Termos para indexação: malformação, Mangifera indica L., Fusarium subglutinans

\section{CULTIVARS BEHAVIOR OF MANGO (Mangifera indica L.) IN RELATION TO MALFORMATION}

ABSTRACT - The malformation of mango caused by the fungus Fusarium subglutinans Wollenweb \& Reinking is probably one of the diseases that causes more damages in the mangoes production in Brazil and other producer countries. This fungus was isolated from a Tommy Atkins plant with advanced symptoms of malformation, purified and prepared to be inoculated in 15 cultivars of national and imported mangoes. Initially, 10 cultivars had been inoculated in July/2000: Bourbon IAC - 100, Coração de Boi, Keitt, Parvin, Primor de Amoreira, Sensation, Smith, Surpresa, Tommy Atkins and Van Dyke. The second group was inoculated in December/ 2000, on the cultivars: Adams, Bhadauran, Palmer, Princesa and Zill, and the inoculation were repeated with others cultivars: Primor de Amoreira, Sensation and Tommy Atkins, with the purpose of comparing the two different times of inoculation. Throughout the data collected at the different times, after 11 months of evaluation, the analysis with $\mathrm{Z}$ mean test was made to compare the averages of unhealthy plants from inoculated cultivars. It can be concluded with the results obtained that the cultivars Bhadauran, Palmer, Parvin, Sensation, Surpresa, Van Dyke and Zill present smaller percentage of plants with malformation symptoms or smaller progression of symptoms in relation to the other inoculated cultivars, under protected environmental conditions, where the assays were carried out.

Index terms: malformation, Mangifera indica L., Fusarium subglutinans

\section{INTRODUÇÃO}

O Brasil incrementou a produção de manga, principalmente com a introdução de cultivares provenientes da Flórida (EUA) através do Instituto Agronômico de CampinasSP, na década de 70, principalmente as cultivares Haden, Keitt, Palmer, Tommy Atkins e Van Dyke (SOARES, 2000).

Segundo RIBEIRO \& PIZA JR., (1989), a malformação da mangueira é um dos piores problemas da mangicultura devido aos prejuízos que causa à produção, sendo que o sintoma mais característico da malformação floral é a redução no comprimento do eixo primário e ramificações secundárias da panícula, que conferem o aspecto de um cacho compacto que é popularmente conhecido como embonecamento.
A malformação vegetativa é mais séria em plântulas e mudas em viveiros, mas a malformação floral causa um impacto significativo à produção de frutos, visto que inflorescências malformadas, normalmente, não produzem frutos. Dessa forma, é um problema mais importante do que a malformação vegetativa (PLOETZ \& PRAKASH, 1997). A maior parte das cultivares de manga são mais ou menos livres de malformação (SINGH et al.,1961).

MALLIK $(1959,1960,1961)$ observou, na Índia, que as cultivares de Bihar e Uttar Pradesh são relativamente livres de malformação, ao passo que aquelas de Maharashtra e Tamil Nadu, que são sadias no seu centro de origem, são seriamente atingidas sob as condições de Bihar. Foi observado que as plantas jovens, provenientes de sementes, são comparativamente menos

\footnotetext{
1(Trabalho 125-2005). Recebido em 16-08-2005. Aceito em 24-11-2006. Parte da Tese do primeiro autor para a obtenção do Título de Doutor em Agronomia - Bolsista da FAPESP (Processo no 98/09851-1)

${ }^{2}$ Engenheiro Agrônomo, Dr., Pós Doutorando do Departamento de Produção Vegetal da FCAV Jaboticabal - UNESP - rzaccaro@fcav.unesp.br

${ }^{3}$ Prof. Titular do Departamento de Produção Vegetal - FCAV Jaboticabal - UNESP

${ }^{4}$ Profa. Titular do Departamento de Tecnologia - FCAV Jaboticabal - UNESP

${ }^{5}$ Prof. Titular do Departamento de Ciências Exatas da FCAV Jaboticabal - UNESP
} 
infectadas que as plantas enxertadas, mas que não há correlação entre intensidade de malformação e a cultivar.

Na Índia também, PRASAD et al., (1965) observaram que a cultivar Bhadauran é a única livre de sintomas de malformação, ao passo que Dashehri, Langra, Malda, Safeda e Chausa são afetadas em 40 a 100\%. No Egito, EL GHANDOUR et al., (1979) constataram que a cultivar Zebda tem comportamento de resistência à malformação.

ROSSETO et al., (1989), em observações realizadas durante sete anos, em cinco municípios do Estado de São Paulo, com 24.900 inflorescências da cultivar Haden, verificaram que $57,2 \%$ eram malformadas e ainda, segundo essas informações, cerca de $57 \%$ da produção da cultivar Haden se perdeu devido à malformação de inflorescências, para as condições do Estado de São Paulo. Consideram também que a malformação varia conforme o ano e o local, com uma nítida diferença entre as cultivares, porém as diferenças não são grandes. Nos pomares comerciais de São Paulo, os maiores danos se concentram na cultivar Tommy Atkins e em menor grau na Haden e Keitt, no caso da malformação floral, e em menor grau, no caso da malformação vegetativa, na cultivar Palmer, mas consideram a malformação, tanto vegetativa quanto floral, o mais sério problema da mangicultura atualmente, em razão dos prejuízos que causa à produção.

Uma avaliação de 19 cultivares, realizada em BebedouroSP, por SOARES, (1994), mostrou que as cultivares mais afetadas foram, Fascell, Keitt, Surpresa, Tommy Atkins, Torbet, Van Dyke e o híbrido 14/51, e as cultivares Dixon, Espada de Ouro, Florigon, Parvin, Pavão e Zill foram consideradas mais tolerantes.

Este trabalho teve o objetivo de estudar o comportamento de 15 cultivares de manga nacionais e importadas através da inoculação do fungo Fusarium subglutinans, mantendo-se as mudas de manga em ambiente protegido, no viveiro de mudas da FCAV - UNESP.

\section{MATERIAL E MÉTODOS}

As cultivares de manga foram enxertadas sobre portaenxerto da cultivar Espada, e formadas em sacos plásticos medindo 20x30 cm, preenchidos com uma mistura em partes iguais de terra, areia e esterco de gado curtido. Foram enxertadas 15 mudas de cada cultivar, para que se pudessem utilizar na inoculação 10 plantas de cada.

Durante os ensaios, foram utilizadas 15 cultivares de manga nacionais e importadas: Adams, Bhadauran, Bourbon IAC100, Coração-de-Boi, Keitt, Palmer, Parvin, Primor de Amoreira, Princesa, Sensation, Smith, Surpresa, Tommy Atkins, Van Dyke e Zill.

O fungo Fusarium subglutinans foi isolado a partir de panículas florais retiradas de uma planta adulta de mangueira da cultivar Tommy Atkins, com acentuados sintomas de malformação, coletados no pomar da FCAV - UNESP. Utilizou-se, para o isolamento do fungo, o meio de cultura BDA com a adição de $100 \mathrm{mg}$ de sulfato de estreptomicina por litro do meio de cultura.

Para o teste de patogenicidade da colônia isolada, foi realizada a inoculação em 2 mudas de cada cultivar: Tommy Atkins, Keitt, Palmer e Haden, utilizando-se de um furador de rolhas de $0,5 \mathrm{~cm}$ de diâmetro, efetuando-se um furo no ponteiro de cada muda, retirando-se a casca. Foi retirada uma porção do meio de cultura com o fungo, colocando-se no ferimento de cada muda, recolocando-se a casca retirada e recobrindo-se com fita crepe. Para o controle, foi utilizada uma planta de cada cultivar, onde se empregou-se o mesmo método de inoculação, sem contudo introduzir-se o fungo.

A inoculação nas cultivares de manga foi realizada primeiramente em 10 cultivares: 'Bourbon IAC-100', 'Coraçãode-Boi', 'Keitt', 'Parvin', 'Primor de Amoreira', 'Sensation', 'Smith', 'Surprêsa', 'Tommy Atkins' e 'Van Dyke'. Nas cultivares Coração-de-Boi e Surpresa, foram inoculadas 9 mudas de cada, pois as outras plantas estavam menores e fora do padrão escolhido para todas as cultivares, que deveriam ter, pelo menos, 2 fluxos de crescimento. Nas demais cultivares, inocularam-se 10 mudas de cada, utilizando-se da mesma metodologia empregada para o teste de patogenicidade.

As 5 cultivares de manga, não-inoculadas na primeira etapa, 'Adams', 'Bhadauran', 'Palmer', 'Princesa' e 'Zill', receberam a inoculação do fungo juntamente com outras mudas das cultivares Primor de Amoreira, Sensation e Tommy Atkins, que já haviam sido utilizadas na primeira etapa com a finalidade de se observar o efeito das duas épocas de inoculação.

Apesar de os sintomas de malformação manifestarem-se normalmente após os 6 meses da inoculação, aos 30 dias, iniciaram-se avaliações para observação de sintomas de malformação vegetativa e floral nas plantas inoculadas.

O delineamento estatístico empregado foi em blocos ao acaso, sendo cada parcela representada por uma planta inoculada. Com os dados obtidos, efetuou-se teste comparativo de médias $\mathrm{Z}$, onde $\mathrm{Z}=\mathrm{p}(\mathrm{p}(1-\mathrm{p}) / \mathrm{n})^{-1 / 2}$, sendo $\mathbf{Z}=1,645$, $\mathbf{n}$ é o número de plantas, portanto $\mathbf{p}=0,26$.

\section{RESULTADOS E DISCUSSÃO}

Com os resultados obtidos nos dois grupos de plantas inoculadas, elaborou-se a Tabela 1, onde se apresentam as duas épocas de inoculação (1 e 2), as plantas sadias e doentes, o tempo de início de sintomas em cada cultivar (INIC. SINT.), a média percentual das plantas com sintomas ao longo dos 11 meses (SINT. \%), a média da percentagem de plantas com sintomas pelo respectivo mês, ao longo dos 11 meses (SINT. $\mathrm{x}$ MES), e a percentagem final de plantas com sintomas (SINT. FIN.).

Com os dados obtidos mensalmente, realizou-se análise de variância em função das fontes de variação envolvidas (Tabela 2), com o teste de médias Z, para a comparação das médias de cultivares, utilizando-se das variáveis: Sintoma (percentual de plantas com sintomas) e do produto sintoma pelo mês. C o m os dados obtidos, efetuou-se a classificação das cultivares, utilizando-se do teste para proporção de plantas doentes (p), baseando-se numa distribuição normal com a fórmula $Z=p(p(1$ $-\mathrm{p}) / \mathrm{n})^{-1 / 2}$, onde $\mathbf{Z}=1,645$, $\mathbf{n}$ é o número de plantas, então $\mathbf{p}=$ 0,26 , portanto para $\mathrm{p} \geq 0,26$, a cultivar será suscetível ao nível de

Rev. Bras. Frutic., Jaboticabal - SP, v. 29, n. 1, p. 115-119, Abril 2007 
0,05 de probabilidade. Desta forma, a classificação das cultivares com base na probabilidade é:

Se $\mathrm{p} \geq 0,26 \Rightarrow$ suscetível;

Se $0,26<\mathrm{p} \leq 0,20 \Rightarrow$ média suscetibilidade;

Se $0,20<p \leq 0,10 \Rightarrow$ baixa suscetibilidade, e

Se $\mathrm{p}<0,10 \Rightarrow$ resistente.

Através da análise, pode-se observar que tanto a média percentual de sintomas (SINT. \%), como a média percentual de plantas com sintomas pelo respectivo mês (SINT. x MES) mostraram significância $(\mathrm{P}<0,05)$ para a época da inoculação, para as cultivares utilizadas e para o mês (período de avaliação). A variável SINT. $x$ MES, que pondera o Sintoma pelo Mês,fornece uma informação adicional da precocidade e intensidade do ataque.

Isto sugere que a época de inoculação, em julho de 2000, deve ter influenciado no desenvolvimento do fungo Fusarium subglutinans nas cultivares inoculadas que se comportaram de forma diferente, visto que a infecção na manga deve ser facilitada pelo maior desenvolvimento vegetativo durante a primavera e o verão. Essa observação é interessante, pois as cultivares Primor de Amoreira, Sensation e Tommy Atkins, que foram inoculadas nas duas épocas, apresentaram, na segunda inoculação, uma taxa de desenvolvimento da doença menor que na primeira inoculação. Pode-se deduzir que isto decorra do fato de que, na inoculação de julho de 2000, as plantas entraram por um período vegetativo intenso na primavera e verão, logo após a inoculação. Por outro lado, na inoculação de dezembro de 2000 , o período vegetativo foi menor, podendo-se traduzir isso como maior dificuldade do fungo em colonizar a planta, diminuindo o ritmo da manifestação dos sintomas. Em relação às observações semelhantes relacionadas à época de início de florescimento e aparecimento de sintomas de malformação, MAJUNDER \& SINHA, 1972, e CHADHA et al., 1979, concluem que as temperaturas que ocorrem durante o período de florescimento e o aparecimento de sintomas de malformação devem obedecer a uma correlação negativa. SHAWKY et al. (1980) observaram que panículas formadas em ramos brotados na primavera foram mais suscetíveis à malformação floral, seguidas em ordem decrescente pelas formadas nos ramos brotados no verão e no começo do outono.

Houve também diferença significativa entre as cultivares inoculadas que, apesar de terem sido utilizadas em pequeno número de plantas, mostraram comportamento diferente em relação à propagação dos sintomas de malformação durante o período de avaliação, podendo-se separar as cultivares em 4 grupos quanto à sintomatologia verificada. Dessa forma, no grupo das resistentes, estariam as cultivares Bhadauran e Sensation; no grupo com baixa suscetibilidade, as cultivares Palmer, Parvin, Smith, Surpresa, Van Dyke e Zill; no grupo com média suscetibilidade, as cultivares Adams e Coração-de-Boi, e no grupo das suscetíveis, as cultivares Bourbon IAC-100, Keitt, Primor de Amoreira, Princesa, Smith e Tommy Atkins. Em relação à cultivar Bhadauran, que não apresentou sintomas em nenhuma planta inoculada, esse resultado coincide com PRASAD et al. (1965) na India, que a apontam como a única cultivar livre de sintomas de malformação em relação às outras cultivares comerciais.

Tabela 1 - Demonstrativo das variáveis avaliadas nas duas épocas de inoculação.

\begin{tabular}{cccccccrrr}
\hline NÚM & ÉPOCA & MÊS & VARIED & SADIA & DOENTE & INÍC.SINT & SINT\% & SINT. x MÊS & SINT. FIN. \\
\hline 1 & 1 & 11 & Bourbon & 7 & 3 & 6 & 11,82 & 109,09 & 30,00 \\
2 & 1 & 11 & Tommy & 7 & 3 & 1 & 20,91 & 154,55 & 30,00 \\
3 & 1 & 11 & C.-Boi & 7 & 2 & 4 & 7,07 & 62,63 & 22,22 \\
4 & 1 & 11 & Surpresa & 8 & 1 & 1 & 10,10 & 65,66 & 11,11 \\
5 & 1 & 11 & Primor & 7 & 3 & 6 & 10,00 & 91,82 & 30,00 \\
6 & 1 & 11 & Parvin & 9 & 1 & 5 & 4,55 & 40,91 & 10,00 \\
7 & 1 & 11 & Keitt & 7 & 3 & 1 & 17,27 & 129,09 & 30,00 \\
8 & 1 & 11 & Smith & 7 & 3 & 5 & 10,91 & 97,27 & 30,00 \\
9 & 1 & 11 & Sensation & 9 & 1 & 1 & 9,09 & 59,09 & 10,00 \\
10 & 1 & 11 & Van Dyke & 9 & 1 & 1 & 9,09 & 59,09 & 10,00 \\
11 & 2 & 11 & Adams & 6 & 2 & 1 & 20,45 & 142,04 & 25,00 \\
12 & 2 & 11 & Bhadauran & 10 & 0 & 11 & 0,00 & 0,00 & 0,00 \\
13 & 2 & 11 & Palmer & 9 & 1 & 8 & 2,73 & 27,27 & 10,00 \\
14 & 2 & 11 & Primor & 10 & 0 & 11 & 0,00 & 0,00 & 0,00 \\
15 & 2 & 11 & Princesa & 4 & 3 & 7 & 9,09 & 90,91 & 42,85 \\
16 & 2 & 11 & Sensation & 10 & 0 & 11 & 0,00 & 0,00 & 0,00 \\
17 & 2 & 11 & Tommy & 8 & 2 & 2 & 16,36 & 114,55 & 20,00 \\
18 & 2 & 11 & Zill & 9 & 1 & 2 & 8,18 & 57,27 & 10,00 \\
\hline
\end{tabular}

NÚM. - número da cultivar inoculada

ÉPOCA - mês da inoculação (julho ou dezembro/2000)

MÊS - período de avaliação (11 meses)

VARIED - cultivar inoculada

INÍC. SINT. - mês de início de sintomas, após a inoculação

SINT. \% - média porcentual de plantas com sintomas ao longo dos 11 meses avaliados

SINT. x MÊS - média do produto do mês e a porcentagem de plantas com sintomas ao longo dos 11 meses avaliados

SINT. FIN. - porcentagem final de plantas com sintomas 
Tabela 2 - Demonstrativo das cultivares agrupadas quanto à suscetibilidade à malformação.

\begin{tabular}{|c|c|c|c|c|c|c|c|c|c|c|c|}
\hline NÚM & ÉPOCA & MÊS & VARIED. & SADIA & DOENTE & INÍC. SINT. & SINT. $\%$ & SINT.x MÊS & SINT. FIN. & & grupo \\
\hline 12 & 2 & 11 & bhadauran & 10 & 0 & 11 & 0 & 0 & 0 & ns & $\mathrm{R}$ \\
\hline 14 & 2 & 11 & primor & 10 & 0 & 11 & 0 & 0 & 0 & ns & $\mathrm{R}$ \\
\hline 16 & 2 & 11 & sensation & 10 & 0 & 11 & 0 & 0 & 0 & $\mathrm{~ns}$ & $\mathrm{R}$ \\
\hline 6 & 1 & 11 & parvin & 9 & 1 & 5 & 4,55 & 40,91 & 10 & ns & B S \\
\hline 9 & 1 & 11 & sensation & 9 & 1 & 1 & 9,09 & 59,09 & 10 & $\mathrm{~ns}$ & B S \\
\hline 10 & 1 & 11 & van dyke & 9 & 1 & 1 & 9,09 & 59,09 & 10 & $\mathrm{~ns}$ & B S \\
\hline 13 & 2 & 11 & palmer & 9 & 1 & 8 & 2,73 & 27,27 & 10 & $\mathrm{~ns}$ & B S \\
\hline 18 & 2 & 11 & zill & 9 & 1 & 2 & 8,18 & 57,27 & 10 & ns & B S \\
\hline 4 & 1 & 11 & surpresa & 8 & 1 & 1 & 10,1 & 65,66 & 11,1111 & $\mathrm{~ns}$ & B S \\
\hline 17 & 2 & 11 & tommy & 8 & 2 & 2 & 16,36 & 114,55 & 20 & ns & M S \\
\hline 3 & 1 & 11 & c.-boi & 7 & 2 & 5 & 7,07 & 62,63 & 22,2222 & $\mathrm{~ns}$ & M S \\
\hline 11 & 2 & 11 & adams & 6 & 2 & 1 & 20,45 & 142,04 & 25 & $\mathrm{~ns}$ & M S \\
\hline 1 & 1 & 11 & bourbon & 7 & 3 & 6 & 11,82 & 109,09 & 30 & $*$ & $\mathrm{~S}$ \\
\hline 2 & 1 & 11 & tommy & 7 & 3 & 1 & 20,91 & 154,55 & 30 & $*$ & $\mathrm{~S}$ \\
\hline 5 & 1 & 11 & primor & 7 & 3 & 6 & 10 & 91,82 & 30 & $*$ & $\mathrm{~S}$ \\
\hline 7 & 1 & 11 & keitt & 7 & 3 & 1 & 17,27 & 129,09 & 30 & $*$ & S \\
\hline 8 & 1 & 11 & smith & 7 & 3 & 5 & 10,91 & 97,27 & 30 & $*$ & $\mathrm{~S}$ \\
\hline 15 & 2 & 11 & princesa & 4 & 3 & 7 & 9,09 & 90,91 & 42,8571 & $*$ & $\mathrm{~S}$ \\
\hline
\end{tabular}

R: Resistente

BS: Baixa Suscetibilidade

MS: Média Suscetibilidade

S: Suscetível

A variável MÊS (período de avaliação) foi significativa e confirma as informações bibliográficas sobre a malformação, que apontam o início de sintomas após os 6 meses da inoculação, conforme ANJOS et al. (1998).

Entretanto todas essas observações não podem ser conclusivas, pois, devido ao pequeno número de plantas de cada cultivar, e as repetições apenas em 3 cultivares, Primor de Amoreira, Sensation e Tommy Atkins, inoculadas nas duas épocas, tem-se uma tendência de que as cultivares Bhadauran, Palmer, Parvin, Sensation, Zill e Van Dyke apresentem menor porcentagem de plantas com sintomas de malformação, ou menor progressão de sintomas em relação às outras cultivares inoculadas, para as condições de ambiente protegido onde foram realizados os ensaios.

\section{CONCLUSÕES}

Os resultados obtidos com a inoculação das mudas das 15 cultivares de manga possibilitaram indicar que as cultivares Palmer, Parvin, Sensation, Van Dyke e Zill apresentem menor incidência de malformação em condições de inoculação artificial, juntamente com a cultivar Bhadauran, que é considerada na Índia resistente à malformação vegetativa e floral.

\section{REFERÊNCIAS}

ANJOS, J. R. N.; CHARCHAR, M. J. A.; PINTO, A. C. Q.; RAMOS, V. H. V. Associação de Fusarium sacchari com a malformação vegetativa da mangueira. Fitopatologia Brasileira, Brasília, v. 23, p. 75-77. 1998.
CHADHA, K. L; PAL, R. N.; PRAKASH, O.; TANDON, P. L.; SINGH, H.; SINGH, N. P.; AO, M. R. K.; LAL, B. Studies on mango malformation: its causes and control. Indian Journal of Horticulture, Bangalore, v. 36, n. 4, p. 359-368, 1979.

EL-GHANDOUR, M. A.; KHADER, A. S.; HUSSEIN, S. A. Some biological, biochemical and nutritional changes in mango tissues in relation with infection with Fusarium moniliforme Sheld. Egyptian Journal of Horticulture, Dokki, v. 6, n. 1, p. 13-22. 1979.

MAJUNDER, P. K.; SINHA, G. C. Seasonal variation in the incidence of malformation in Mangifera indica L. Acta Horticulturae, Wageningen, 24, p. 221-223, 1972.

MALLIK, P. C. Mango malformation. In: SEMINAR DISEASES OF HORTICULTURAL PLANTS, 1959, New Delhi. Proceedings...

MALLIK, P. C. Studies on the malformation of the mango inflorescence. Bihar: Academy of Agricultural Sciences, 1960. p. 8-9.

MALLIK, P. C. Studies on the malformation of mango inflorescence. In: INDIAN SCIENCES CONGRESS, 48., 1961. Roorkee. Proceedings... p. 501-502.

PLOETZ, R. C.; PRAKASH, O. Foliar, floral and soilborne diseases. In: LITZ, R. E. (Ed.) The mango: botany, production and uses. Wellingford:CAB International, 1997. p. 299-302.

PRASAD, A.; SINGH, H.; SHUKLA, T. N. Present status of mango malformation disease. Indian Journal of Horticulture, Bangalore, v. 22, p. 254-265, 1965.

RIBEIRO, I.J.A.; PIZA JR., C.T. Controle de moléstias da mangueira. In: SIMPÓSIO SOBRE MANGICULTURA, 2., 1989. Jaboticabal. Anais... p. 113-132. 
ROSSETO, C. J.; RIBEIRO, I. J. A.; GALLO, P. B.; CARVALHO, R.

P. L. Pragas da mangueira e seu controle. In: SIMPÓSIO SOBRE MANGICULTURA. 2., 1989, Jaboticabal. Anais... p. 133-148.

SHAWKY, I.; ZIDAN, Z.; EL-TOMI, A.; DAHSHAN, D. I. Flowering malformation in relation to vegetative growth of 'Taimour' mangoes. Egyptian Journal of Horticulture, Dokki, v. 7, n. 1, p. 1-8, 1980.

SINGH, B.; SINGH, S. M.; NIRVAN, R. S. Studies on mango malformation, review, symptons, extent, intensity and causes. Horticultural Advance, Saharanpur, v. 5, p. 197-207, 1961.

SOARES, N. B. Comportamento de dezenove variedades de mangueira (Mangifera indica L.) na região de Bebedouro, São Paulo. 1994. 142 f. Tese (Doutorado) - Faculdade de Ciências Agrárias e Veterinárias, Universidade Estadual Paulista, Jaboticabal. 1994.

SOARES, N.B. Mangueira. In: MELETTI, L.M.M. Propagação de frutíferas tropicais. Guaíba: Agropecuária, 2000. p.178-187. 